\title{
CONOCIMIENTO EN TORNO AL AEDES AEGYPTI Y LA TRANSMISIÓN VECTORIAL DE ENFERMEDADES EN YUCATÁN. BIOLOGÍA Y ANTROPOLOGÍA, DIÁLOGOS INTERDISCIPLINARIOS ${ }^{1}$
}

\author{
G. H. Angelotti Pasteur ${ }^{*}$ y P. Peniche Moreno ${ }^{* *}$ \\ Universidad Autónoma de Yucatán ${ }^{*}$ y Centro de Investigación y Estudios Superiores en Antropología Social ${ }^{* *}$ \\ gabrielotti@yahoo.com*
}

Submetido em 13/03/2017- Aceito em 20/05/2017

DOI: $10.15628 /$ holos.2017.5782

\section{RESUMEN}

El conocimiento de la biología y la entomología médica sobre la transmisión vectorial de enfermedades es relevante para comprender fenómenos socio-históricos en torno al proceso de salud/enfermedad. Explicar, por ejemplo, cómo se relacionan los hábitos y ciclos de reproducción del Aedes aegypti con fenómenos como la urbanización creciente, la contaminación y degradación ambiental, la distribución desigual de la riqueza o los servicios que presta el Estado, develan la complejidad que entraña enfrentar la generación y reproducción de las Ilamadas enfermedades emergentes. Este trabajo apunta hacia ese diálogo necesario. Con un enfoque social sobre la vulnerabilidad y la construcción social de riesgos, con una preocupación sociohistórica sobre las condiciones de producción y reproducción de las enfermedades, y con la metodología de la etnografía, el artículo se basa en una entrevista realizada a un biólogo en la que el discurso y el conocimiento se estructura interdialógicamente.

PALABRAS CLAVE: Aedes aegypti, enfermedades causadas por vector, Biología, Antropología, Interdisciplina.

\section{KNOWLEDGE ABOUT AEDES AEGYPTI AND VECTOR-BORN DISEASES IN YUCATAN.}

\section{BIOLOGY AND ANTHROPOLOGY, INTERDISCIPLINARY DIALOGUES}

\begin{abstract}
The knowledge from biology and medical entomology related to vector-Borne diseases is relevant for understanding socio-historical phenomena around the health/disease process. To explain, for example, how Aedes aegypti's habits and reproductive cycles are related to phenomena such as increasing urbanization, pollution and environmental degradation, or the unequal distribution of wealth or services provided by the State, reveals the complexity around the generation
\end{abstract}

and reproduction of emerging diseases. This work points to this necessary dialogue. The interview presented was made with a social focus on vulnerability and social construction of risks, with a sociohistorical concern about the conditions of producto on and reproduction of diseases, and with the methodology of ethnography.

KEYWORDS: Aedes aegypti, vector-Borne disseases, biology, anthropology, interdiscipline 


\section{1. INTRODUCCIÓN}

Durante los años de 2015 y 2016, cuando en Yucatán se vivieron los primeros brotes de chikungunya y zika, tuvimos una posición realmente privilegiada para observar críticamente la problemática de las enfermedades emergentes en nuestro estado: como científicos sociales, investigábamos el proceso de salud/enfermedad/atención y sus determinantes socio-históricas; como divulgadores, iniciamos entrevistas a distintos expertos en la materia y pudimos aprender mucho y agudizar nuestra mirada; como ciudadanos, vivíamos en una ciudad, y en un estado, que estaba siendo afectado seriamente por una enfermedad transmitida por el Aedes aegypti; nosotros mismos enfermamos y enfermaron nuestras familias, $y$, de este modo, observamos las acciones del gobierno, la forma en que el tema fue tratado en los medios de comunicación masiva y la postura que las autoridades de salud local asumieron ante el problema. Haciendo trabajo de campo etnográfico en comunidades mayas del oriente de Yucatán, fuimos testigos directos del impacto de la primera epidemia de fiebre chikungunya que se vivía en el estado.

Sin embargo, las enfermedades transmitidas por los mosquitos han sido parte de la historia misma de la Península de Yucatán desde tiempos remotos (GÓNGORA-BIACHI, 2000 y 2014). Desde el siglo XVI, la malaria y la fiebre amarilla selvática causaron serios estragos en la población (THOMPSON, 1997, p. 83-85); en el siglo XVII hizo su aparición la fiebre amarilla urbana, volviéndose endémica hasta las primeras décadas del siglo XX (DOMíNGUEZ AMAYA, 2013; PÉREZ, 2016). Dado el impacto que generaban estas enfermedades en la salud pública, tras el movimiento revolucionario, Yucatán se sumó a las campañas que se hicieron a nivel nacional y continental para eliminar a los mosquitos transmisores de enfermedades (BUSTAMANTE, 1996). Fue hasta 1963 que se declaró oficialmente que se había logrado exterminar el vector de la fiebre amarilla, mientras que el combate a los mosquitos transmisores del paludismo continuó hasta varias décadas después. Tras un breve impasse de diez años, de nueva cuenta nos enfrentamos al Aedes aegypti, ahora con la transmisión emergente del virus del dengue en 1970, del chikungunya en 2015 y del zika en 2016.

El clima cálido, la vulnerabilidad de los sistemas de salud y la deficiente infraestructura urbana son algunas de las causas que han favorecido la reproducción de los mosquitos y la proliferación de estas enfermedades. En el 2015 la fiebre chikungunya afectó a miles de yucatecos, provocando el colapso del sistema de salud de la región que fue rebasado por el número de personas enfermas.

A partir de datos de la Dirección General de Epidemiología (DGE) de la Secretaría de Salud, se calcula que entre 2014 y 2015 el aumento de la morbilidad de enfermedades transmitidas por el Aedes aegypti a nivel nacional fue de 19.3\%, mientras que en Yucatán el problema fue grave, dado que alcanzó el $190 \%$ de incremento. De los 3129 reportes oficiales recibidos por la DGE en 2015, el 52\% se trató de fiebre chikungunya (BOLETín EPIDEMIOLÓGICO, 2015). En pocos meses el número de enfermos se incrementó y para septiembre las autoridades de salud pública de Yucatán, alarmadas, comenzaron a informar respecto del incremento de casos locales. Las salas de espera de los hospitales de la ciudad de Mérida estaban atiborradas de pacientes reclamando atención. Al mismo tiempo, la única medicina empleada para mitigar los síntomas (el "Paracetamol" conocido también como acetominofén) comenzó a escasear, tanto en el sistema de salud oficial como en las farmacias comerciales (PENICHE Y ANGELOTTI, 2017). Por las calles 
de la ciudad de Mérida y en las localidades del interior del estado, era común ver a personas caminando "como viejitos": espalda corva, paso lento y cansino. Esto evidenciaba que habían sido víctimas de la enfermedad. La magnitud del problema fue tal, que el ausentismo laboral en Yucatán alcanzaría cifras históricas, calculándose alrededor del 10 al $15 \%$ entre los meses de agosto y noviembre (los de mayor impacto).

En el 2016 el país tuvo que prepararse ante una eventual pandemia de zika, de acuerdo con la alerta declarada desde finales del 2015 por la Organización Mundial de la Salud. A diferencia de lo ocurrido un año anterior, las noticias corrieron pronto, así como las advertencias emitidas a las mujeres embarazadas, que llegaron a atemorizar a la población, generando un clima de tensión. Al finalizar el año, y según los reportes oficiales, se supo que el total de enfermos de zika alcanzó la cifra de 820.

En los siguientes cuadros registramos el número de enfermos de dengue y dengue hemorrágico según consta en el conteo efectuado desde el sector oficial.

\begin{tabular}{|l|l|l|l|l|l|l|}
\hline & 2012 & 2013 & 2014 & 2015 & 2016 & total \\
\hline Dengue & 3157 & 1844 & 627 & 1129 & 267 & 7024 \\
\hline $\begin{array}{l}\text { Dengue } \\
\text { hemorrágico }\end{array}$ & 2497 & 914 & 434 & 327 & 123 & 4295 \\
\hline Total & 5654 & 2758 & 1061 & 1456 & 390 & 11319 \\
\hline
\end{tabular}

Figura 1: Casos de dengue en Yucatán. Fuente: Boletín Epidemiológico Nacional 2016 (México).

Mientras que para las enfermedades emergentes del chikungunya y zika, las cifras para el estado de Yucatán fueron las siguientes:

\begin{tabular}{|c|c|c|c|c|c|c|}
\hline & 2012 & 2013 & 2014 & 2015 & 2016 & Total \\
\hline chikungunya & 0 & 0 & 1 & 1627 & 11 & 1639 \\
\hline Zika & 0 & 0 & 0 & 0 & 820 & 820 \\
\hline
\end{tabular}

Figura 2: Enfermedades por vector en Yucatán, chikungunuya y zika. Fuente: Boletín Epidemiológico Nacional 2016 (México).

Como observadores directos, advertimos lo poco o nada que la población en general sabía sobre estas enfermedades (chikungunya, zika y dengue); advertimos lo poco o nada que la población sabía sobre el vector. Al inicio, fue común que se atribuyeran los primeros síntomas a la fiebre del dengue, dada la experiencia que ya se tenía con esta enfermedad a nivel regional. Poco tiempo pasó, sin embargo, para que se reconociera que en esta ocasión las altas temperaturas corporales eran distintas, y los dolores musculares y articulares intensos. 
Es un hecho que el conocimiento científico en el campo de la biología, bioquímica, medicina, epidemiología, virología y entomología, entre otras disciplinas, se ha incrementado de manera importante; y que las acciones en el campo de la salud pública han sido continuas y persistentes en los últimos 100 años, a fin de erradicar los vectores, y se han empleado métodos químicos (fumigación, abatización, uso de repelentes) y físicos (empleo de mallas protectoras, descacharrización), promoviéndose tanto la acción individual, como colectiva. Sin embargo, pese a estos esfuerzos $y$, no obstante, la larguísima experiencia histórica que tenemos con las enfermedades transmitidas por vector en Yucatán, los resultados alcanzados en este estado han sido negativos y muestra de ello fue lo vivido durante el 2015 y 2016.

\section{2. REVISIÓN BIBLIOGRÁFICA}

Las principales enfermedades transmitidas por vector en la Península de Yucatán que han llamado la atención de los científicos sociales son el paludismo y la malaria. El caso prehispánico ha sido tratado por Thompson (1997) quien propone que la malaria pudo haber tenido un efecto muy negativo en la sociedad maya clásica. Para la época colonial, la fiebre amarilla ha sido abordada por las graves consecuencias que tuvo en el siglo XVII, y se ha estudiado su impacto en la agricultura y la economía de la época (GARCÍA BERNAL, 1978; FARRISS, 1992; PENICHE, 2010; PÉREZ, 2016). A partir de 1648, tras su primera irrupción, la fiebre amarilla se volvió endémica en la región, causando severos estragos en la población hasta 1923, cuando se documentó el último caso en el puerto de Veracruz (TORRES, 1995). Algunos de los aspectos que ha desarrollado la historiografía en torno a la fiebre amarilla son las campañas de erradicación realizadas durante el porfiriato y la posrevolución (GÓNGORA, 2004; DOMÍNGUEZ, 2013; CANTO, 2015); la participación de organismos internacionales en su combate (THEILER Y DOWNS, 1973; LÖWY, 1997); los esfuerzos históricos encaminados a la erradicación de vectores en la primera mitad del siglo XX (ORTIZ Y TORRES, 1964; SOPER, 1968; MUÑOZ, 1995; SOLÓRZANO, 1996); el pensamiento médico dominante en torno a la enfermedad (ALCALÁ, 2012); la relación de la enfermedad con el comercio y la producción henequenera a finales del siglo XIX (MENÉNDEZ, 1981).

También desde la óptica histórica, se han analizado las campañas de erradicación de la malaria en la primera mitad del siglo XX (BYNUM Y OVERI, 1985; CUETO, 2005); y del dengue a partir de 1970 (BRATHWAITE, 2012).

Las enfermedades transmitidas por vector han llamado menos la atención de la antropología, pero, aun así, podemos contar trabajos que desde esta óptica abordan su ecología política (ORTIZ, 1984; LEWONTIN Y LEVINS, 1996; ALMENDARES, 2009), su etnoecología (WIHEFORD, 1997), y el vínculo de estos problemas de salud con fenómenos como la urbanización y la transición en salud en México (KENDALL, 1991).

\section{METOdOLOGÍA}

Ante el panorama vivido en 2015 nos preguntamos ¿Por qué las enfermedades transmitidas por vector no se han logrado erradicar? ¿Por qué se ha incrementado el número de enfermos por vector en México y Yucatán? Y, además, ¿Qué factores han favorecido el ingreso de nuevos virus transmitidos por mosquitos en Yucatán?

Con el fin de responder algunas de estos interrogantes, en 2016 iniciamos un proyecto titulado: "Enfermedades transmitidas por el mosquito Aedes aegypti en Yucatán: efecto del 
dengue, chikungunya y zika en 2015 y 2016. Reportaje multimedia" y cuyos resultados pueden consultarse en la red, ya que son de libre acceso. ${ }^{2}$ Las premisas que orientaron este proyecto fueron dos: 1) que el proceso de salud/enfermedad/atención se construye mediante representaciones, prácticas y saberes, 2 ) que la divulgación del conocimiento científico es una forma de incidir en los saberes e intervenir en el ciclo de producción y reproducción de las enfermedades.

Con estas ideas en mente, realizamos numerosas entrevistas a científicos, médicos alópatas, yerbateros, encargados del área de salud en el sector rural y a personas que habían padecido estas enfermedades. ${ }^{3}$

Con un enfoque social sobre la vulnerabilidad y la construcción social de riesgos, con una preocupación sociohistórica sobre las condiciones de producción y reproducción de las enfermedades, y con la metodología de la etnografía, el artículo se basa en una entrevista realizada a un biólogo en la que el discurso y el conocimiento se estructura interdialógicamente. La entrevista que presentamos se desprende de este proyecto. ${ }^{4}$ La misma fue realizada al Dr. Julián García Rejón, Profesor-Investigador del Departamento de Virología del Centro de Investigaciones Regionales "Hideyo Noguchi" de la Universidad Autónoma de Yucatán, especialista en enfermedades infecciosas y transmitidas por vector. El material fue videograbado y parte de su contenido fue incluido en el Reportaje Multimedia citado. ${ }^{5}$ Para la antropología, la entrevista abierta es un método sustancial del ejercicio etnográfico; una entrevista, no cerrada ni previamente estructurada, sino que mediante el diálogo construye el discurso y socializa el conocimiento. Como parte de este ejercicio etnográfico, hemos editado y añadido algunas notas a pie de página, con el afán de facilitar la comprensión sobre algunos conceptos y términos científicos, propios del campo de la entomología. Por cuestión de estilo, evitamos identificar a los interlocutores, y destacar en negritas la pregunta.

\section{ENTREVISTA A UN ENTOMÓLOGO}

\section{- ¿Cuál es su especialidad?}

Julián García Rejón - Yo soy biólogo de licenciatura. Estudié en la UADY, luego una maestría y posteriormente un doctorado en la Universidad Autónoma de Nuevo León, ambos con especialidad en entomología médica, en insectos que transmiten patógenos. Ya de ahí empecé a encaminarme hacia la parte de los virus; obviamente, el que más nos importa, es el dengue. Entonces he trabajado con mosquitos que transmiten el dengue, aunque también he trabajado con otro mosquito que igualmente vive en las casas, el Aedes albopictus que es vector de diferentes virus, como del Oeste del Nilo y algunas encefalitis, tanto en México como otras partes.

\section{- ¿A qué se dedica el laboratorio en el que usted trabaja?}

JGR - Éste es un laboratorio de arbovirología, que son virus transmitidos por artrópodos. ${ }^{6}$ Dentro de los principales artrópodos, están los insectos, pero también hay otro grupo que son los arácnidos. El mosco es el principal vector de arbovirus; pero por la parte de los artrópodos también tenemos a las garrapatas, que parecen insectos pero no lo son. ${ }^{7}$

\section{- En caso del mosco Aedes aegypti ¿Cuándo llega a Yucatán?}

JGR - El origen del mosquito Aedes aegypti obviamente es africano: una parte de su nombre viene de Egipto, o sea aegypti. ${ }^{8}$ Antiguamente el nombre "Egipto" denominaba a una buena parte de África. Se cree que muy probablemente llegó a América con la colonización, con las invasiones de los españoles y de las diferentes poblaciones; primero pudo haber llegado a Europa y de Europa para acá, o bien directamente de África. ${ }^{9}$ 
En Yucatán, que es el área donde nosotros trabajamos, se tenía conocimiento de la existencia de una enfermedad que se llama fiebre amarilla, que los cronistas refieren como una enfermedad extraña que causa un vómito negro y que en maya se llama xeek $i k .{ }^{10}$ Se creía que había una asociación entre los monos y los humanos. Pero nada más eso, no se sabía quién lo transmite ni nada más. Entonces, de la que estoy hablando es realmente es la fiebre amarilla; esta fiebre amarilla es provocada por un virus, un arbovirus transmitido por un vector y que generalmente causa daño hepático. Este daño hepático se caracteriza porque las personas enfermas vomitan como reflujo de sangre; y esta sangre generalmente ya está coagulada. Entonces es un problema que ocasiona la muerte.

El ciclo natural de esa enfermedad involucra a los monos y mosquitos, no necesariamente Aedes aegypti. ${ }^{11}$ Cuando llegan los colonizadores a Yucatán y mencionan esta enfermedad, en un principio sabían que se daba en la selva realmente, pero después empiezan a documentar casos de esta enfermedad dentro de las casas. Entonces se cree que el Aedes aegypti probablemente fue el vector de esta fiebre amarilla domiciliada.

\section{- ¿El mosquito pudo viajar en barco desde África y así llegar a América?}

JGR - Perfectamente, durante la Colonia pudo haber venido en un barco, probablemente, en estado adulto. Allí mismo pudo haber depositado sus huevos en las barricas donde se almacenaba agua y, de este modo, nació una nueva generación de insectos, la cual habría comenzado a alimentarse de sangre humana infectada, y continuó con el ciclo de contagio.

\section{- ¿Por qué muchos de los virus ubican su origen en África?}

JGR - Esa es una muy buena pregunta, realmente. No es tanto que en África haya más cosas de lo que nosotros tengamos, sino que muchos virus se conocieron buscando la fiebre amarilla. $\mathrm{O}$ sea, confundiéndose que eran casos de fiebre amarilla, se determinó que no lo eran, sino que eran otros virus. Por eso es que se conoce, por ejemplo, el virus del zika, la primera vez que se describió fue en los bosques de Zika en África; el virus del chikungunya, también buscando fiebre amarilla se encontró, y fue en África. La primera vez que se encontró fue ahí, porque ahí siempre hay muchos problemas de fiebre amarilla. Igual, también, en parte de Sudamérica; en la parte del Amazonas, que hay mucha zona silvestre, es una selva, hay muchos casos de fiebre amarilla de animales. Y cuando el humano se incorpora, por estar ahí, y sí no está vacunado y se infecta, pues generalmente puede ocasionar lo peor.

\section{- ¿Qué es un vector?}

JGR - Los vectores, en este caso, son artrópodos que pueden transmitir una enfermedad; hay diferentes categorías de vectores. Un vector realmente es un acarreador; en el caso de las matemáticas es como si fuese una dirección, una flecha. Pero en el caso de los parásitos, patógenos, virus, etcétera, los vectores pueden haber de muchas maneras. Puede ser un vector mecánico, como el caso de las moscas que se posan en un lugar donde hay una bacteria y después se posan sobre un alimento, y uno después se come el alimento, pero se come también las bacterias. Entonces es un acarreador, en ese caso la mosca.

En el caso del mosquito: dentro del mosquito sucede un cambio, ya sea del virus, del patógeno, etcétera, y después este virus es transmitido por este insecto. En el caso del virus del dengue, el virus es tomado de una persona que está enferma y en la cual, como tiene fiebre, el virus está circulando en todo su cuerpo. Toma el virus de la sangre de esta persona enferma y posteriormente pasa el proceso mediante el cual tiene que metabolizar la sangre; de la parte posterior de su cuerpo va regresando el virus, una cuestión bastante extraña, en un gradiente de la parte posterior a la parte primaria que es la cabeza, para alojarse en las glándulas salivales en una cantidad mucho mayor de virus.

\section{- Entonces ¿el virus cambia dentro del mosco?}


JGR - Se multiplica, se replica muchas veces más. Entonces, por decir, si entra una cantidad menor, cuando llega a las glándulas salivales se potencializa en millones de veces.

\section{- Ese proceso, ¿afecta al mosco?}

JGR - No, no lo afecta, entre comillas... o sea, realmente hay cambios. El virus hace cambiar al mosquito, por ejemplo, cuando el mosquito está infectado del virus del dengue, aparentemente el virus y las glándulas salivales tienen problemas y el mosquito tiene dificultad para alimentarse. Se tarda un poquito más en alimentarse, entonces, ¿Qué es lo que sucede? Llega el mosquito, va hacia una persona, se empieza a alimentar, pero no es fácil su alimentación; entonces normalmente las personas sentimos que nos están picando, lo espantamos, el mosquito vuela, pero no ha terminado de alimentarse, y necesita otra persona. Pero entonces a la primera persona con la que se empezó a alimentar, ya la contagió, y ahora tiene que buscar otra, y también la va a contagiar. Entonces, sí ustedes se dan cuenta, el virus ya está ahí asegurando de que a más personas se lo va a transmitir.

\section{- ¿Cómo se alimenta el mosco?}

JGR - El mosquito es hematófago, ${ }^{12}$ el mosquito hembra; cuando se está alimentando va excretando la saliva, pero también algunas sustancias enzimáticas que ocasionan que esta sangre no se coagule, porque sí no, se tapa y ya no podría estar succionando. Lo que realmente hace, es que rompe parcialmente una pequeña vena y de esa pequeña vena se forma un pequeño charquito, y de ahí va tomando pequeños sorbos; sí, y va tomando la sangre; como va excretando la saliva y esas sustancias que hacen que no se permita la coagulación, puede seguir tomando, pero dentro de la saliva si hay el virus, lo va transmitiendo. Cabe mencionar que esas sustancias que va secretando el mosquito, hacen que algunas personas -después de que se alimente el mosquito de ellos- les ocasione rasquera, picazón, ardor, y pues es lo que nosotros sentimos y a veces nos tallamos tanto que se nos hace una pequeña lesión que se podría contaminar.

\section{- Entonces ¿Para qué succiona sangre?}

JGR - El primer mosquito que hubo en el mundo no era hematófago; siempre se han alimentado de las sustancias dulces de las plantas, los néctares. Como una abeja, se alimenta de los néctares y toma estas sustancias dulces que le aportan los carbohidratos, con los cuales se puede mover de un lado a otro, puede volar y puede hacer otras tantas cosas que hace. Entonces, los artrópodos tienen una característica muy particular de su comportamiento que es buscar nuevas formas de alimentación. Hay una teoría que se llama "La teoría de la nidalidad", que explica que estos artrópodos en un momento dado se quedaron encerrados con algún organismo mamífero, principalmente, y entonces no había otra cosa más para comer. Se cree que, en un principio, con esa característica de probar cosas, empezaron a probar la lagrima, el sudor, cosas que excreta el organismo. Con el tiempo se fueron haciendo un poquito más especializados y se atrevieron un poco más.

Ya entonces hubo un pequeño cambio con respecto al aparato de alimentación, ya se le formo una [proboscis] ${ }^{13}$ la cual le permitía poder traspasar la piel y poder tomar un líquido. La sangre tiene muchas proteínas, pero también tiene grupos hemáticos que están cargados con hierro, está la hemoglobina; este tipo de sustancias hace que los huevecillos de los mosquitos sean más viables, tengan mayor capacidad de poder tener éxito, de poder tener un crecimiento adecuado. De hecho, en el caso de Aedes aegypti, es tanta su especialización, que la sangre del humano es la que le permite mayores nutrientes. Entonces esto condiciona que trate de alimentarse del humano, más que de otra cosa.

\section{- ¿También puede alimentarse de otros mamíferos?}

JGR - Sí, realmente se pueden alimentar de animales, pero no les transmite el virus, al menos no se les desarrolla la enfermedad del dengue como tal, como a nosotros. Pero, lo más importante, 
es que la sangre del humano le proporciona más nutrientes que cualquier otra sangre, y la trata de buscar. El caso del mono y la fiebre amarilla, es que es como un reservorio. En las enfermedades, hay algunos que son huéspedes accidentales; ${ }^{14}$ los reservorios son los que reservan y mantienen cierto parásito, ciertos virus etc. en la naturaleza. Hay ciertos huéspedes, también terminales, que son donde se acaba la enfermedad, ahí mueren, y pues esos no sirven; el ciclo lo que quiere es preservarse. En el caso de los animales, de los otros mamíferos, hay ciertas condiciones que su sistema inmune que no permiten que se adapten bien esos virus, entonces no manifiestan una enfermedad. Eso no quiere decir que no tengan contacto con el virus; sí puede haber una cuestión de que su sistema inmune lo detecte, que nosotros le hagamos una prueba de detección y encontremos anticuerpos contra determinado virus. ¿Qué quiere decir? Que probablemente el virus tuvo contacto con él o con su sistema inmune pero no quiere decir que se haya enfermado.

\section{- ¿Cuánto tiempo vive un mosquito?}

JGR - El mosquito hembra vive, aproximadamente, de un mes a un mes y medio. Y se alimenta de sangre cada cuatro, cinco días.

\section{- ¿Y qué sucede con los mosquitos en la época de "seca", se mueren?}

JGR - Bueno, realmente es un poco complicado porque nosotros acá, en nuestro medio, no tenemos época de frío intenso, en la que nieve. Si hubiese eso, tal vez ahí podría haber una latencia. Yo creo que durante la sequía permanecen vivos los huevecillos. Pueden sobrevivir toda la época de seca. Que, en el caso de Yucatán, es de solo tres meses, no más.

- ¿Esto significa que ante una pequeña llovizna los mosquitos vuelven a "salir"?

JGR - Sí, porque son oportunistas, y mientras haya esa posibilidad de agua, la van a emplear para multiplicarse. Ese es el éxito de un organismo vivo: la facilidad en la reproducción y su mantenimiento. En Yucatán, la gente cree que luego de una lluvia los mosquitos "salen" de la hierba. En realidad, esta confusión surge porque el periodo de crecimiento del pasto es similar al tiempo de crecimiento de los mosquitos. Es decir, de una semana. Esta asociación visual no es real porque en las hierbas no hay agua. Allí los mosquitos pueden alojarse y alimentarse de néctar y azúcar; y también encuentran refugio ante los depredadores.

\section{- ¿Los mosquitos pican en cualquier parte del cuerpo?}

JGR - El mosquito Aedes aegypti, hasta dónde sabemos, prefiere picar en las piernas y los pies, aquellos lugares del cuerpo que no están al alcance de nuestras manos. Además, ellos prefieren alimentarse cuando nosotros estamos descansando, sentados, comiendo o viendo televisión. Es decir, momentos en los que estamos ocupados o, distraídos. Esta situación es aprovechada por el mosquito para picarnos y succionar sangre.

\section{- ¿Por qué no duelen las picaduras de ciertos mosquitos?}

JGR - A diferencia de los tábanos, cuyas mordeduras son muy dolorosas, algunas picaduras de mosquitos son imperceptibles. En el caso particular del Aedes aegypti su picadura puede no ser detectada porque estos gustan de picar por las mañanas o por las tardes, momentos en los cuales el cuerpo está activo. En cambio, los mosquitos que se alimentan de noche, son detectados porque escuchamos el zumbido que emiten. En este sentido conocer el ciclo de vida de los mosquitos es fundamental para que sepamos como debemos protegernos.

\section{- ¿Qué lugares u objetos prefieren los mosquitos hembras para desovar?}

JGR - De los que conocemos, las llantas usadas de automóviles son los objetos que poseen las mejores características para los mosquitos ¿Por qué será así? Pues, porque están hechos de caucho que permite la acumulación de agua y mantiene una temperatura adecuada para los huevecillos. Incluso en las llantas los mosquitos suelen trasladarse de un lugar a otro. Hasta en las bolsas de patitas fritas se pueden reproducir, porque, generalmente, son laminadas; realmente 
es un excelente criadero. Dentro del ciclo de vida del mosquito, en la parte acuática, las larvas necesitan bacterias para alimentarse; entonces, para que se formen las bacterias tiene que haber cierta materia orgánica que haga que se produzcan. Y, por ejemplo, una bolsita de papitas, es como un caldo de cultivo perfecto para las bacterias. Entonces eso es un plus todavía, realmente todo es una cuestión de un mal manejo de lo que ya no sirve, que debiese de estar en un lugar donde debería, como en un basurero.

\section{- ¿Cómo es su copulación y cuántos huevecillos puede poner una hembra?}

JGR - Las hembras copulan una vez, y no lo vuelven hacer en su vida. Los machos, en cambio, pueden copular con muchas hembras. En una población de mosquitos es importante que existan muchas hembras, de ese modo se puede asegurar la propagación de la especie. En total, la hembra puede poner doscientos huevecillos, dependiendo de la cantidad y calidad de la sangre con la que se haya alimentado. También, varía si es la primera vez. La particularidad de las hembras de Aedes aegypti es que nunca ponen sus huevecillos en un solo recipiente y de una sola postura, sino que los dispersan en lugares distintos. Hasta los objetos más pequeños pueden servir para que las hembras depositen sus huevecillos. Por ejemplo, en una corcholata ${ }^{15}$ puede depositar dos o tres huevos. Luego, en una lata de frijoles, o de refresco, otros veinte o treinta. El resto los puede depositar en un florero u objeto similar. Incluso, se puede dar el caso que distintas hembras depositen huevos en u mismo recipiente. Ello provoca un pool genético. ${ }^{16}$

\section{- ¿Qué proporción de hembras y machos nacen?}

JGR - Nacen en igual proporción, cincuenta y cincuenta por ciento. Es importante saber que primero salen los machos y luego las hembras. Como en esos momentos los mosquitos no pueden volar, porque tienen las alas frescas, los depredadores, ranas $u$ otros organismos, aprovechan para comerlos y saciarse. Luego, cuando los depredadores ya quedaron satisfechos, salen las hembras.

\section{- ¿Cuánto es el tiempo de vida de las hembras?}

JGR - La hembra puede vivir dos meses, aunque puede llegar a tres. Claro, siempre que las condiciones de vida sean las adecuadas y que no existan depredadores.

- ¿Qué particularidad tiene el mosquito que prefiere ámbitos domésticos en lugar de ámbitos salvajes? ¿Siempre fue así o se adaptó a la vida humana?

- El Aedes aegypti realmente era un mosquito salvaje, vivía en los montes; tenía criaderos naturales como pueden ser charcos de agua, pedazos de cocos cortados, etc., cualquier lugar donde se pudiese almacenar agua, de lluvia generalmente.

Entonces, el Aedes aegypti, como tiene la preferencia de la alimentación sanguínea humana, pues busca estar cerca de nosotros, esa es la principal característica. Entonces se fue acomodando a los criaderos que nosotros le poníamos, nosotros le fuimos dando los sitios donde él se podía reproducir. Por ejemplo, un florero en las casas -son muy comunes-, que si tiene plantas acuáticas; ya después con la basura, el mal manejo de la basura de los contenedores, por ejemplo, las bolsas de las papitas, de las "Sabritas", los recipientes pet (tereftalato de polietileno). La sociedad que ha ido cambiando, cada vez hay nuevas cosas, nuevos empaques. También influye el problema del suministro del agua: en algunas zonas como el norte de México el agua no es tan común y no llega a todas partes, entonces las personas tienen que almacenar su agua, en barriles etc., y esos lugares son ideales para el Aedes aegypti, porque no tienen que batallar; por decirlo de alguna manera, todos los mosquitos son oportunistas, ante una oportunidad la aprovechan, eso es básico.

- ¿Cómo es la vida de los mosquitos al interior de nuestras viviendas?

JGR - En nuestras viviendas solemos facilitar la vida a los mosquitos Aedes aegypti. Allí encuentran lugares protegidos, espacios oscuros y húmedos, que son de su preferencia. Si 
nosotros ingresamos a una vivienda de Mérida, por ejemplo, una casa de fraccionamiento, en las habitaciones y dormitorios encontraremos numerosos mosquitos. Esto sucede porque ellos se esconden en la ropa, preferentemente, aquella de color negro y tonos oscuros. También se guarecen debajo de las camas y en los roperos. Así sucede siempre, especialmente, luego que se alimentan de sangre. Cuando esto sucede, ellos no pueden volar y se mueven mediante brinquitos, pequeños saltos. En este punto el mosquito es muy vulnerable y los depredadores se pueden aprovechar de su estado. Allí suelen quedarse hasta que termina la digestión. Otro lugar preferido son las salas y comedores. Allí suelen esconderse en los muebles. También prefieren los baños. En realidad, hay mosquitos en cualquier rincón de la vivienda, incluso en la cocina, detrás de los refrigeradores, etcétera.

\section{- ¿Qué cantidad de mosquitos han encontrado en las viviendas de la ciudad de Mérida?}

JGR - Bueno, sí nosotros entráramos a una casa en plena temporada de mosquitos encontraríamos aproximadamente, entre cincuenta hasta sesenta mosquitos. De esa cantidad, tres cuartas partes serían de la especie Culex quinquefasciatus y un cuarto de Aedes aegypti. El Culex quinquefasciatus es el mosquito café que en la región todo el mundo conoce, y es el más abundante. Este solo puede ser vector de diferentes enfermedades, de diferentes paracitos. En el caso de los perros transmiten la Dirofilaria inmitis, una enfermedad común en nuestro ambiente. Pero, eso sí, no transmite los virus ni del zika ni del chikungunya. Respecto los mosquitos Aedes aegypti, una proporción de los veinte, dieciocho son hembras. Esto sucede porque después de copular, los machos se quedan al exterior de las viviendas y las hembras se refugian en el interior. Por el contrario, si hacemos una inspección en los patios exteriores y jardines, es probable que encontremos mayor cantidad de machos que de hembras.

- ¿Hay en Yucatán algún sector social que se más vulnerable que otro? Se piensa que la zona sur $^{17}$ es más vulnerable que en la norte de la ciudad de Mérida ¿Es cierto?

JGR - Bueno, casi todo tiene explicación. Sabemos, por ejemplo, que los mosquitos viven con nosotros, en nuestras viviendas, en los lugares de trabajo, escuelas, oficinas y todo espacio donde habiten los humanos. Y si hay mosquitos Aedes aegypti, es probable que las personas se enfermen de dengue, chikungunya o zika. Sucede que las personas se protegen de formas diferentes. En algunas familias no existe "la cultura del miriñaque". ${ }^{18}$ En otras no se toman las medidas apropiadas para tratar la basura. Estos factores incrementan las posibilidades de reproducción de los mosquitos, por ende, las posibilidades de virus que provocan enfermedades. Con respecto a las cuestiones de la transmisión mucho tiene que ver con la cantidad de personas que habitan en la vivienda. A mayor cantidad de habitantes, mayores serán las posibilidades de contagio, en caso que alguien adquiera la enfermedad. Ante el hecho de presentarse un caso, es probable que todos se contagien de lo mismo. En las viviendas los mosquitos pican a todos los integrantes: mamá, papá, hermanos, tía, tíos, abuelos, etc. De allí que una medida adecuada para evitar los contagios es la de aislar a los enfermos y, de este modo, disminuir la exposición de las personas sanas a los mosquitos. Porque al tener el virus circulante, todos los mosquitos que tengan contacto con esta persona se van a infectar. Entonces, si nosotros estamos cuidando al enfermo y no nos estamos protegidos (no tenemos repelente, no tenemos nada) muy probablemente también nosotros nos enfermemos.

\section{- ¿Cuál es el papel de los mosquitos en la naturaleza?}

JGR - Esto siempre me lo han preguntado; porque todo mundo dice, bueno, ¿Y para qué sirve un mosquito? Los mosquitos sí tienen un papel muy importante, y por eso no de que es posible erradicar a los mosquitos. ¿Qué pasa si matamos a todos los mosquitos? Porque eso es lo que quieren todos. 
Todos los organismos tenemos una función, biológicamente hablando. La primera y más importante es que -como ya lo mencioné- se alimentan de las sustancias dulces, son polinizadores como las abejas; también los mosquitos hacen esa función, esa es la principal. Pienso yo que otra de sus funciones es que sirve a la cadena trófica, o sea, hay que verlo como un organismo: muchos organismos, muchos depredadores se alimentan de ellos; en ocasiones, casi exclusivamente, como, por ejemplo, los besucones o las cuijas. Las cuijas, esos son un muy buen aliado en las casas, desgraciadamente mucha de la población las mata.

- ¿Qué sucede si lográramos eliminar a todos los mosquitos?

JGR - Bueno, si se acabaran los mosquitos, ello tendría una implicación fuerte en la naturaleza. Primero, porque son polinizadores; aunque no sabemos a qué especie de plantas beneficia. Tampoco sabemos si son mejores polinizadores que las abejas $u$ otros animales. El segundo aspecto tiene que ver con los propios depredadores para los cuales el mosquito es su alimento preferido ¿Qué van a comer en su lugar? ¿Abejas, otros insectos? Aún no lo sabemos. El tercer aspecto es el siguiente: en la naturaleza cuando desaparece una especie, otra ocupa su lugar. De modo que si matamos a los mosquitos puede suceder que otro insecto se transforme en una nueva amenaza o plaga para los humanos.

- Después de la campaña que realizó la Fundación Rockefeller ${ }^{19}$ tan exitosa para erradicar la fiebre amarilla ¿Qué pasó con los vectores? ¿Realmente desaparecieron? ¿Cómo es posible que a los pocos años hayan resurgido?

JGR - Sí, la campaña fue buena. Y es importante decir que la fiebre amarilla es una enfermedad que, por su sintomatología, es bastante desagradable, pudiendo ocasionar la muerte de los pacientes. Por el impacto que produjo entonces, fue que se emprendió esa campaña a nivel mundial y se fumigó con DDT. ${ }^{20}$ El DDT es uno de los insecticidas que más ayudó a los humanos. Hay que decirlo con estas palabras. Nos ayudó a erradicar la fiebre amarilla y a combatir el paludismo. En África, por ejemplo, hoy día se sigue empleando. Cuando ya no hay nada más que hacer, se emplea DDT. Es un insecticida potente, bastante agresivo. Realmente acaba con los mosquitos. Afecta a todos los insectos, pero en un principio afecta a los mosquitos. Me consta, yo lo vi, el DDT tiene una eficacia total.

- ¿Han generado los mosquitos resistencia a este insecticida?

JGR - No, porque se dejó de usar. En este sentido hay que ser honestos: desde mi punto de vista, como experto, yo no creo que se haya acabado con todos los mosquitos, no creo que se los haya erradicado en su totalidad. Lo que sucedió fue que se los pudo controlar, y la vacunación ayudó en este sentido.

- Es decir, ¿La enfermedad disminuyó por qué redujeron el número de vectores del virus?

JGR - Exactamente, eso fue lo que pasó. Conforme fue pasando el tiempo, ya empezando los setenta, comenzó a conocer el problema que provocaba el DDT en la salud y el ambiente, de sus implicaciones y su permanencia en la naturaleza, etc. $Y$ dejó de utilizarse. Pudo suceder que la población de mosquitos comenzara a recuperarse. Por eso, según creo, fue que no se erradicó, sino que se disminuyó y el mosquito siguió estando presente. Cuando "entra" el virus del dengue comprobamos que el problema no había sido solucionado. El mosquito Aedes aegypti no había desaparecido, estaba aquí.

\section{- ¿Nos puede contar algo de Hideyo Noguchi?}

JGR - Sí, claro. Hideyo Noguchi ${ }^{21}$ fue un investigador japonés que investigó la fiebre amarilla en diversos lugares tropicales del mundo. Por esta razón estuvo en Yucatán un tiempo y trabajó en el hospital O'Horan. Quienes lo conocieron, dicen que fue una persona muy amable, accesible y que afín de compartir sus logros y conocimientos. Por ese entonces en Japón era considerado una eminencia. Incluso uno de los billetes de ese país tiene la figura de Hideyo Noguchi. El 
impacto de su visita a Yucatán fue enorme. Para nosotros era un honor contar con alguien tan importante.

\section{- ¿Luego él enfermaría de fiebre amarilla?}

JGR - Exactamente. De eso murió. Esto nos enseña una lección, saber que nadie está exento de una enfermedad infecciosa, mucho menos de enfermedades como el dengue, chikungunya y zika. Estas no hacen diferencias. No importa el grado académico o de estudios, el nivel económico o social. Los mosquitos pican a todos por igual. Al final de cuentas, a los mosquitos, solo les interesa alimentarse de sangre humana.

- En otros países, como ocurre en Cuba, hay una política de estado mediante la cual se puede intervenir a nivel privado. En nuestro país eso, por el momento, no es posible.

JGR - Sí. Aunque en Cuba sigue habiendo casos de dengue, año con año, seguramente hubo chikungunya y muy severo. Pero no tenemos información oficial para saber el tamaño de la gravedad. Cuba y Mérida, son similares en cuestiones climáticas, altitud, etcétera. En ambos lugares encontramos una estación de lluvia muy marcada. Una época del año en la cual llueve fuerte y con frecuencia, la cual facilita la reproducción de los mosquitos y el incremento en los casos de enfermedades.

\section{- ¿Cuál es el mejor método para combatir a los mosquitos?}

JGR - El mejor método es aquel que se pueda utilizar por mucho tiempo, que permite ejercer un control lo menos invasivo posible y que, a largo plazo, no ocasione problemas, como sí ocurrió con el DDT. Además, que se pueda aplicar fácilmente. Pero este tipo ideal no existe. Por eso hablamos de aplicar controles integrales que incluyan controles químicos, mediante la utilización de larvicidas, insecticidas cuando se requiera sea rociando o fumigando; controles físicos, mediante la descacharrización ${ }^{22}$ con ayuda de la labor comunitaria y controles biológicos, mediante el empleo de depredadores como peces, la utilización de bacterias como el Bacillus thuringiensis. Lo que buscaremos con estos métodos es evitar que nos afecten los patógenos, que son quienes nos provocan las enfermedades. No se trata de matar mosquitos. El control debe tener un impacto contra el patógeno que transmite el mosquito. Dentro de estos métodos de control tenemos que incluir a las vacunas, debido a que estas permiten inmunizar a las personas $y$, de este modo, contribuir a la disminución del número de sujetos susceptibles a enfermarse. Este es la idea principal de todo el esfuerzo que, desde diferentes frentes, se pueda controlar una enfermedad.

Realmente debe haber un engranaje de todos los métodos. Además, la aplicación de insecticidas debe realizarse según las normas oficiales mexicana contra las enfermedades transmitidas por vector. $^{23}$ Las cuales manejan ciertos parámetros donde se define con claridad el tipo de insecticida que podemos utilizar, su cantidad, en qué proporción, cuándo, qué hacer cuando encontramos casos de dengue, etcétera. Allí se encuentran todas las indicaciones que se deben seguir. Si me preguntan si son las indicadas. Ahí no lo sabría decir, porque nosotros no participamos en su elaboración. Pero, lejos de criticar, tenemos que colaborar, todos estamos expuestos a estas enfermedades, incluso su servidor. De manera que todos estamos interesados en que las medidas sean útiles. Sin embargo, en la realidad encontramos hechos que no están contemplados en esas normas y sobre los cuales no hay respuestas. Por ejemplo, en nuestra región, si tenemos problemas derivados de un ciclón, tenemos que atender problemas derivados de esta circunstancia. Así, como hay temporada de huracanes, sería importante saber que hay temporadas en las que se transmiten más estas enfermedades por los mosquitos en la cual tenemos que aplicar distintas medidas preventivas, por ejemplo, proveernos de repelentes, de ropa adecuada, un pabellón y checar los miriñaques. Todas estas indicaciones son las que, idealmente, deben aplicarse para evitar el problema y guiar a la población para que extreme 
precauciones ante estas enfermedades. El tema no es sencillo, y nuestras acciones deben estar apegadas a las normas, que son nuestra guía.

\section{COMENTARIOS FINALES}

La presente entrevista deja al descubierto el interés que existe en el sureste de México, en específico, en el Estado de Yucatán, sobre las enfermedades provocadas por vectores, y, en particular, por los mosquitos. En parte, esto ha sucedido porque la región ha sido afectada por estos insectos, los cuales han provocado numerosas epidemias. El afán de encontrar respuestas a estos problemas fue un estímulo para los académicos locales, que ha impulsado la investigación y la labor aplicada. En este derrotero la Universidad Autónoma de Yucatán, con el departamento de virología del Centro de Investigaciones Biomédicas, ha jugado un rol significativo en el estudio de las enfermedades tropicales.

Al interés primigenio de biólogos y entomólogos, en los últimos años, se ha sumado el de académicos del ámbito de las ciencias sociales, en específico, del campo de la Antropología Social y la Historia. De este modo, la comunidad científica local busca generar conocimiento científico veraz que, de aplicarse apropiadamente, permitirá reducir el número de los vectores y, por su efecto, de las enfermedades que ellos transmiten. Las campañas de reducción de mosquitos, así como todas las acciones dedicadas a la prevención, para ser efectivas, deberán estar regidas por conceptos científicos y no por otro tipo de intereses o fines. Además, y como señala en la entrevista, será fundamental involucrar a la sociedad civil, a los ciudadanos. De ese modo, aprovecharemos la experiencia, conocimientos tradicionales y trayectorias de las comunidades en la promoción de la salud- y alcanzar una mayor eficacia de las acciones ejecutadas.

\section{REFERENCIAS BIBLIOGRÁFICAS}

1. ALMENDARES, J. (2009). "Ambiente, salud y derechos humanos. Hacia una continuada política ecológica". Ecología Política, (37), 59-63.

2. BRATHWAITE DICK, O., SAN MARTÍN J. L., H. MONTOYA ROMEO, JORGE DEL DIEGO, ZAMBRANO BETZANA, \& H. DAYAN GUSTAVO. (2012). "Review: The History of Dengue Outbreaks in the Americas". Am. J. Trop. Med. Hyg., (87(4)), 584-593.

3. BROWN, R. (1980). Rockefeller Medicine Men. Medicine and Capitalism in América. California: University of California Press.

4. BUSTAMANTE, M. (1986). “Un descubrimiento científico truncado en 1912, el de la fiebre amarilla de la selva en Yucatán". Conferencia magistral. Gaceta Médica de México. Vol. 122. Nov. dic. 1986. 263-272.

5. BYNUM, W. F., Y OVERY, C. (1998). The Beast in the Mosquito: The Correspondence of Ronald Ross and Patrick Manson. Atlanta: Rodopi.

6. CÁMARA MILÁN, P. (2000). “El Dr. Hideyo Noguchi en Yucatán”, Rev Biomed; 11: 207-212.

7. CANTO, R. (2015). La fiebre amarilla en Yucatán, 1903-1920. Entre el deseo de la erradicación y la realidad del control. Las razones de una lucha sanitaria inconclusa. Tesis de doctorado en historia, Mérida: CIESAS.

8. CARSON, R. (2016). Primavera silenciosa. México: Grupo Planeta (original de 1962). 
9. CUETO, M. (2005). “Appropriation and Resistance: Local Responses to Malaria Eradication in Mexico, 1955-1970". Journal of Latin American Studies, 37(3), 533-559.

10. DOMínGUEZ AMAYA, A. J. (2013). Pensamiento médico y política sanitaria: colera y fiebre amarilla en Mérida, Yucatán. 1891-1917. Tesis. UADY.

11. FARRISS, N. (1992), La sociedad maya bajo el dominio colonial, Madrid: Alianza Editorial.

12. GARCÍA BERNAL, M.C. (1978). Población y encomienda en Yucatán bajo los Austrias, Sevilla: Consejo Superior de Investigaciones Científicas.

13. GARCÍA GÓMEZ, C., ET. AL. (2011). "La segregación territorial y el rezago en el sur de la ciudad de Mérida como el resultado del crecimiento urbano descontrolado". Quivera, vol. 13, núm. 1, enero-junio, 2011, pp. 122-138. Toluca: Universidad Autónoma del Estado de México.

14. GÓNGORA-BIACHI, R. (2000), "La Fiebre Amarilla en Yucatán durante las épocas precolombina y colonial", Revista Biomedica, 2000; 11: 301-307.

15. GÓNGORA-BIACHI, R. (2004). "La erradicación de la fiebre amarilla en Mérida, Yucatán: una historia de tenacidad y éxito". Revista Biomédica, 15(4), 251-258.

16. GÓNGORA-BIACHI, R. (2014). "La erradicación de la fiebre amarilla en Mérida, Yucatán: una historia de tenacidad y éxito", Revista Biomedica 2004; 15:251- 258.

17. JIMÉNEZ CISNEROS, B.E. (2001). La contaminación ambiental en México. Causas, efecto y tecnología apropiada. México: Femisa-UNAM.

18. Kendall CARL CARL KENDAL, PATRICIA hUdELSO, H. P., ELLI LEONTSIN, L. E., PETER WINCH, W. P., LINDA LLOYD, L. L., \& FERNANDO CRUZ, C. F. (1991). “Urbanization, Dengue, and the Health Transition: Anthropological Contributions to International Health. Medical Anthropology Quarterly, 5(3), 257-268.

19. LANDA, DIEGO FRAY DE. (1982). Relación de las cosas de Yucatán, México: Miguel Ángel Porrúa.

20. LEWONTIN, R., Y LEVINS, R. (1996). “El regreso de las viejas enfermedades y el nacimiento de las nuevas". Ecología Política, (12), 107-110.

21. LÖWY, I. (1997). "Epidemiology, Immunology, and Yellow Fever: The Rockefeller Foundation in Brazil, 1923-1939". Journal of the History of Biology, 30(3), 397-417.

22. MENÉNDEZ, E. (1981). Poder, estratificación y salud. Análisis de las condiciones sociales y económicas de la enfermedad en Yucatán (Ediciones de La Casa Chata). México: CIESAS.

23. MUÑOZ TORRES, A. (1995). "La fiebre amarilla en México. Erradicación del Aëdes Aegypti". Salud Pública De México, 37, 103-110.

24. ORTIZ MARIOTTE, C. (1984). "La fiebre amarilla selvática en México". Boletín de la Sociedad Mexicana de Geografía y Estadística, 135.

25. ORTIZ MARIOTTE, C., Y A. TORRES MUÑOZ (1964). "Protección antiaédica en México", Salud Pública De México, VI (5), 803-807.

26. AUTORA, P. (2010), Tiempos aciagos. Las calamidades y el cambio social del siglo XVIII entre los mayas de Yucatán, México: Miguel Ángel Porrúa/CIESAS. 
27. AUTORA Y AUTOR (2017). "Familia y enfermedades emergentes. Modelos de atención y representaciones culturales de la fiebre chikungunya entre la población maya”, manuscrito.

28. PÉREZ AMÉZQUITA, W. (2016). Otra ciudad de Nínive: epidemias y hambrunas en Yucatán, 1648-1716. Tesis de maestría en historia. Mérida: CIESAS.

29. SOLÓRZANO, A. (1996). "La influencia de la Fundación Rockefeller en la conformación de la profesión médica mexicana, 1921-1949”. Revista Mexicana de Sociología, 58 (1, enero-marzo), 173-203.

30. SOPER, F. L. (1968). "EL Aedes aegypti y la fiebre amarilla". Boletín de la Oficina Sanitaria Panamericana, 187-196.

31. TELLO SOLÍS, E. (1988). "La vida en Yucatán durante el gobierno del Conde de Peñalba: verdades y trebejos". Mérida: Universidad Autónoma de Yucatán.

32. THEILER, M., Y W. G. DOWNS. (1973). The arthropod-borne viruses of vertebrates. An account of The Rockefeller Foundation Virus Program, 1951-1970, London: Yale University Press.

33. THOMPSON, E. (1997). Historia y religión de los mayas. México: Siglo XXI.

34. WHITEFORD, L.M. (1997). "The Ethnoecology of Dengue Fever". Wiley on behalf of the American Anthropological Association., 11(2), 202-223.

\section{HEMEROGRAFÍA:}

35. "Con todo y médicos extra, dengue y chikungunya satura servicio del IMMS". Milenio. Novedades. 13 de septiembre de 2015. Consultado en línea: http://sipse.com/milenio/denguechikungunya-atencion-imss-servicios-salud-169711.html

36. "Hospitales saturados con enfermos de Chikungunya". Cadena Rasa. 8 de septiembre de 2015. Consultado en línea: http://www.notirasa.com/?seccion=noticia-detalle\&id=23871

37. "Se multiplican problemas por dengue y chikungunya". Milenio Novedades. 16 de septiembre de 2015. Consultado en línea: http://sipse.com/milenio/dengue-chikungunya-imssfiestas-patrias-servicios-medicos-yucatan-170118.html

38. "Empresas yucatecas, afectadas por enfermedades vectoriales". Milenio Novedades. 13 de septiembre de 2015. Consultado en línea: http://sipse.com/milenio/empresas-yucatecasausentismo-laboral-enfermedades-causadas-mosco-221819.html

39. "El impacto económico y social por el chikungunya no puede soslayarse". Milenio Novedades. 15 de septiembre de 2015. Consultado en línea: http://sipse.com/milenio/chikungunya-canacome-turismo-economia-enfermedad-salud-dengue169932.html

40. Daño empresarial. Más ausentismo laboral por causa del chikungunya". Diario de Yucatán. 1 de octubre de 2015. Consultado en línea: http://yucatan.com.mx/merida/economiamerida/dano-empresarial

\footnotetext{
${ }^{1}$ Entrevista realizada al Dr. Julián García Rejón, entomólogo, especialista en enfermedades infecciosas y transmitidas por vector. UADY La presente entrevista fue revisada y aprobada por el Dr. Julián García Rejón.
} 


2 La dirección para consultar el Artículo Multimedia es la siguiente:

http://mosquitoyuc.wixsite.com/pmosquitoyucatan

${ }^{3}$ En el Reportaje Multimedia difundido en la red exponemos estos materiales visuales y sonoros. También pueden consultarse en la página de Youtube donde están alojados con la leyenda "Proyecto mosquito 2016". La siguiente dirección corresponde al documental: https://www.youtube.com/watch?v=7slz9mYj1iU

En total se realizaron 6 entrevistas a científicos el área de la salud y 11 testimonios a personas que padecieron estas enfermedades. Otros testimonios fueron incluidos en el siguiente video documental: https://www.youtube.com/watch?v=7slz9mYj1iU

${ }^{4}$ Extractos de esta entrevista pueden verse en el video documental difundido en internet, la dirección es la siguiente: https://www.youtube.com/watch?v=H3EeCRyblsY

${ }^{5}$ El cual se puede consultar en la siguiente dirección: https://www.youtube.com/watch?v=H3EeCRyblsY

${ }^{6}$ Los arbovirus es el nombre que se la ha dado a un conjunto de virus transmitidos por artrópodos, del inglés arthropod-borne viruses (virus llevados por artrópodos). Los artrópodos son “del grupo de los invertebrados, de cuerpo con simetría bilateral cubierto por una cutícula y formado por una serie lineal de segmentos más o menos ostensibles, y provisto de apéndices compuestos de piezas articuladas", como insectos, crustáceos o arañas. RAE.

${ }^{7}$ Las garrapatas transmiten diferentes virus, el principal es uno que se llama Lengua Azul. Pueden también llegar a transmitir bacterias que causen encefalitis, como "Encefalitis de la Fiebre de las Montañas".

${ }^{8}$ En cuanto al origen del término Aedes, la interpretación más aceptada es que se deriva del adjetivo griego aedés

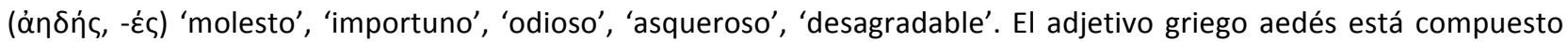

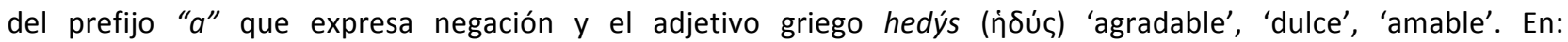
http://hispanoteca.eu

${ }^{9}$ Presumiblemente en los barcos que transportaban esclavos.

${ }^{10}$ Desde finales del siglo XV se hacen menciones de la fiebre amarilla en escritos como el Popol Vuh en donde se indica que "el vómito de sangre" estaba presente desde 1480 a 1485 . Al respecto Landa menciona que existieron brotes entre $1483-1484$, describiéndola como xekik, término en maya que se traduce literalmente como "vómito de sangre", Landa, 1973.

${ }^{11}$ La fiebre amarilla selvática es transmitida por un mosquito del género Haemagogus. A diferencia de los mosquitos del género Aedes, los de este género habitan en áreas selváticas y forestales, y las hembras depositan sus huevecillos en las copas de los árboles, principalmente. Theiler y Downs, 1973.

12 Hematófago: dicho de un animal, que se alimenta de sangre, Real Academia española en línea.

${ }^{13}$ Apéndice alargado y tubular situado en la cabeza de un animal. Su uso más común es para comer y absorber.

${ }^{14}$ Huésped es el individuo en el cual se aloja el parásito y le proporciona condiciones para su subsistencia como alimento, estímulo hormonal para su maduración sexual, y para su crecimiento o simplemente protección; el huésped definitivo permite al parásito desarrollar formas adultas y sexuadas; el huésped intermediario tiene formas en desarrollo, o que se reproducen de manera asexuada; el huésped accidental es aquél en el cual el parásito no reside comúnmente, porque las condiciones no son adecuadas para su desarrollo, y en consecuencia no puede completar su ciclo evolutivo, en Gallegos, Parasitología.

${ }^{15}$ Tapa de refrescos embotellados.

${ }^{16}$ Entendido como el acervo genético de una especie o población.

${ }^{17}$ La zona norte de la ciudad de Mérida presenta mejores condiciones sociales y económicas, recibe mejor atención por las autoridades municipales. En su mayoría las calles están asfaltadas, tiene servicio de agua potable, los terrenos son amplios y cuenta con parques arbolados. El nivel de vigilancia policial es importante y en este sector se alojan las familias de mayor poder adquisitivo. Por el contrario, el sur (algunos dicen "el sur profundo") padece de numerosas carencias en los servicios básicos. Al respecto se puede consultar el trabajo de Carmen García Gómez, et. Al. (2011) "La segregación territorial y el rezago en el sur de la ciudad de Mérida como el resultado del crecimiento urbano descontrolado". Quivera, vol. 13, núm. 1, enero-junio, 2011, pp. 122-138. Universidad Autónoma del Estado de México Toluca, México.

${ }^{18}$ En Yucatán denominan miriñaque a los protectores realizados con tela mosquitera que suelen colocarse en las ventanas para evitar el ingreso de insectos a las viviendas.

${ }^{19}$ Esta campaña se dio a nivel continental en todo América, se emprendió en la primera mitad del siglo XX y gracias a ella en 1923 se declaró en México el último caso de fiebre amarilla. Brown, 1980.

${ }^{20}$ DDT = Diclorodifeniltricoloroetano o 4-4 DDT, el insecticida de mayor uso debido a que es insoluble en agua, resiste la luz y la oxidación. También, es el más estable químicamente. Ha sido empleado para combatir numerosas enfermedades en el mundo: tifo, mosquitos transmisores de malaria, paludismo, entre otros. Se emplea en agricultura y en la lucha vectorial. En México es de uso restringido. (Jiménez Cisneros, Blanca Elena (2001), La contaminación ambiental en México. Causas, efecto y tecnología apropiada. Femisa-UNAM-México. P: 99. Para 
profundizar sobre el tema se recomienda leer el libro clásico de Rachel Carson Primavera Silenciosa (1962), un texto relevante que influyó en la decisión de prohibir el DDT en el mundo.

${ }^{21}$ Nació en la ciudad de Wakamatsu, Japón, el 24 d noviembre de 1876 y se graduó de Doctor en Medicina en 1898. Trabajó en Estados Unidos, Dinamarca y en 1904 fue invitado para integrarse a los laboratorios del Instituto Rokefeller de New York. En estudia la fiebre amarilla y en 1920, enviado por el Instituto Rockefeller, llega a Mérida, investiga sobre la fiebre amarilla en los laboratorios del Hospital O'Horán. En 1928, estando en África, fallece por causas de esta misma enfermedad (Cámara Milán, Pedro, 2000, El Dr. Hideyo Noguchi en Yucatán, Rev Biomed 2000; 11:207-212).

22 De cacharro, vasija o recipiente. RAE.

${ }^{23}$ Se refiere a la "NORMA Oficial Mexicana NOM-032-SSA2-2010, Para la vigilancia epidemiológica, prevención y control de las enfermedades transmitidas por vector", misma que se puede consultar en la siguiente dirección: http://www.cenaprece.salud.gob.mx/programas/interior/vectores/descargas/pdf/nom_032_ssa2_2010_norm a_petv.pdf 